\title{
An Empirical Study about the Impact of Work-family Conflict on Female Staff's Career Development in Hotels
}

\author{
Xiaoman Zhou ${ }^{1} \&$ Biyan Wen ${ }^{1}$ \\ ${ }^{1}$ School of Management, Jinan University, Guangzhou, China \\ Correspondence: Xiaoman Zhou, School of Management, Jinan University, Guangzhou, 510632, China. E-mail: \\ 1eej0304@163.com
}

Received: July 21, 2016 Accepted: August 23, 2016 Online Published: September 27, 2016

doi:10.5539/jsd.v9n5p100

URL: http://dx.doi.org/10.5539/jsd.v9n5p100

\begin{abstract}
Hotel industry is a labor-intensive industry for women and the proportion of women in the hotel industry is large while the number of women managers has also increased. However, the traditional gender, social support and work-family conflict and other various factors make the career development of women managers in hotels relatively more resistance. Work-family conflict has significant impacts on both work and family. Therefore, the paper chose the female middle managers in hotels as the research object, and used literature research and questionnaire method to gather data. Then, the reliability of scales was measured by SPSS19.0, and we performed the principal component analysis to measure the reliability of variables.After that, we conducted variance analysis to clarify the different stages of work and family lives as well as different departments whether have different influences on female middle managers. The paper analyzed the objective existence of universality, causes and the effects of work-family conflict for female middle managers in hotels. On this basis, the paper proposed some ways to ease the work-family conflict, such as implementing flexible management to weaken the time conflict, paying attention to females' demands and take the mission of helping employees to achieve a balance, and designing family supporting programs for female managers to promote female advantages of middle managers, to promote the development of hotel female human resources and alleviate the negative impact of work-family conflict on female managers' career development.
\end{abstract}

Keywords: work-family conflict, female in hotels, middle managers, balance program

\section{Introduction}

Every stage of career development is closely linked with family. Staff experience professional lives as well as family lives. In addition, family lives have great significance to staff and influence their professional lives. Therefore, the balance between work and family is particularly important for female staff.

Work-family relations theory is one of the theoretical bases of the career development of females. According to the literature review, we found that work and family are different systems, but they interact each other. The behavior and affairs of work and family always both nest and influence one another. Moreover, changes of society have improved the individual responsibilities under different circumstances, so that the relationship between work and family is evolving and the theory of work-family relations is also developing. Because of the different growth patterns, different stages of lives and different roles expectations, the demands for men and women are also differentiated. The undulatory requirements and development of females depend on their occupation-family life stage, and the relationship between work and family is in a dynamic evolving.

Female middle managers play the connecting link role in hotels and they shoulder greater pressure. On the one hand, they have to pay attention to families since their children are young and there are at least two elderly people in need of care. What's more, their husbands are already on an uptrend in the work that need more support from his wife. So, the family burdens and responsibilities of women middle managers are heavy. On the other hand, this stage is also the the rising phase of female managers. The organization requires more comprehensive quality to bear responsibilities and they need to devote more time to learning, training, taking further education. So, female middle managers in hotels face intense work-family conflict, and their physical and psychological pressure is great. Therefore, the paper chose the female middle managers in hotels as the research object. Based on work and family relations theory, we tried to find out the mechanism of mutual influence between work and family. Firstly, the paper established the factors of career development of female middle 
managers in hotel industry, then analyzed the performance and impact of various factors, and analyzed the objective existence of universality, causes and the effects of work-family conflict. On this basis, the paper proposed some ways to ease the work-family conflict in order to promote female advantages of middle managers, to promote the development of hotel female human resources and alleviate the negative impact of work-family conflict on female managers' career development.

\section{Literature Review}

From the literature review, we found that work-family conflict was formally introduced to the sociology research in 1950 around. With the increased competition among enterprises, a large number of women walked into the workplace which broke the original work-family balance and the pressure from work and family were enhanced. Professional women play different roles in the work and family areas. There are different expectations for different roles and when women can not reconcile the divergent role requirements, it will inevitably produce conflicts.

Work-family conflict is a contradiction of roles between work and family.It described the phenomenon that the requirements of work are incompatible with the requirements of another character,namely family and it is difficult to fulfill all expectation (Luo, 2012). Greenhaus \& Beutell (1985) divided the work-family conflict into three types: time conflict, pressure conflict and behavior conflict. Time conflict refers to the time or attention distract between the two areas, but due to the schedule conflicts and time restriction, the requirements of out field can not be satisfied. Pressure conflict describes the phenomenon that the stress of one character makes it is hard to complete another role's requirements. Behavior conflict refers to the behavior of individual in one field does not meet the demands of other fields while the individual can not adjust and convert well between the two roles.

Professional women have to assume multiple social roles. However, they are always limited by the traditional social role expectations. The family responsibilities of women are more prominent than men which inevitably leads more work-family conflict after they entering the career field (Yang, 2012). Pleck (1984) found that working men spend time on housework only one-half of their wives and spent on children only two-thirds, while women spend more time on family activities than men during the whole lives. Moreover, women experience more conflicts between work and family at the earlier stage of the family life cycle.Nadine F Marks (1998) done some empirical research from psychological satisfaction point to study the gender differences on work-family conflict issue. He indicated that caregiver role is a good reflection of the gender differences when facing and dealling with work-family conflict and people who assumes the role of caregiver have to experience more conflicts than non-caregivers. Further,domestic scholars also got the similar results on this research. Shi (2015) pointed out that compared with male employees,female employees are more vulnerable to work-family conflict.

According to the previous research on female managers' career development in hotels, Brownell (1991) showed that although the number of female and male who graduated from hotel management is consistent, the ratio of women leaving the industry is three times higher than men. Brass (1985) proposed that the most common obstacles of women career development are men working close relationships and lack of guidance which primarily refer to women are being excluded from many informal information networks and they have difficulties obtaining information related to career development. Chusmir (1986) considered family obligation is an important factor affecting women work lives and marital status has a great impact on pursuing career development. Brownell (1994) proved that the men working close contradictory relationships, work-family conflict, unequal treatment and promotion are major barriers of women career development by questionnaire study in his article. At the same time, he found that the number of single manageress in hotels is significantly larger than single male managers which implies the particularity of the hotel environment determines that women must pay a high price. What's worse, because of long and irregular working hours, constantly adjustment of internal and external relations, female managers have to postpone or to change marriage. American human resource expert Robert Whelan published an article on the hotel and catering management of Cornell University. He pointed out that female managers' position in hotels is rising but still low. On the positive side,they have their own unique characteristics and gender advantage on management. The research on this topic are rather little in China. Chen (2003) studied from the characteristics of hotel industry and the management characteristics of females, she thought that women are more suitable for hotel management and the their gender advantages can improve the hotel's human resources management and customer relationship management. Moreover, she pointed out that the special status of women managers in hotels including the spirit of service, the better access dominance and so on.

The research on the career development of the female managers in the hotel industry has a certain theoretical 
basis, but one criticism of much of the literature is that scholars have paid less attention to empirical research than theoretical analysis to explore the possibilities to reduce the hazard of work-family conflict. So, we chose the female middle managers in hotels as the research object,then analyzed the objective existence of universality, causes and the effects of work-family conflicts. On this basis, we proposed some ways to ease the work-family conflict to take full female advantages of women managers, to promote the development of hotel female human resources and alleviate the negative impact on female managers' career development in hotels.

\section{Hypotheses}

Staff experience professional lives as well as family lives and the balance between career and family responsibilities is important for them, especially for female staff. The pressure derived from marriage and parenthood sometimes beyond the pressure of a job or career,while the impact of work-family conflict among employees even more obvious than personal goals of career development (Zhang, 2002). Individuals have a variety of options and even adverse selection in the social lives, but we, as children or parents, is irreversible. We can give up a profession life, but can not give up these roles. On the contrary,we have to try to accomplish these responsibilities (Edgar H. Schein, 1992). The paper proposed the following hypotheses from five aspects which are job satisfaction, organizational commitment, job burnout, job performance and turnover intention of female middle managers in hotels to explore the impact of work-family conflict on their career development.

Kopelman et al. (1983) put forward a role conflict model based on previous research about the work-family conflict. In this model, work conflicts refers to the stress come from the confusion of incompatible roles. Family conflict describes the phenomenon that the requirements of family are incompatible. Role conflict refers to the stress of one character makes it is hard to complete another role's requirement. Job satisfaction of female employees are influenced by the combined impact of work-family conflict and norms and expectations of different roles. When the time, stress and behavior conflicts are intense, the job satisfaction of female middle managers will be affected negatively. On the basis of these considerations, we posit the hypotheses:

\section{H1: work-family conflict has a significant passive impact on job satisfaction.}

Meyer \& Allen (1990) defined the organizational commitment as psychological states of employees and these states reflect the attitude of the staff to organizational relationships. They thought that the organizational commitment includes the following aspects: emotional commitment, normative commitment and continuance commitment. Liu (1999) summarized the factors that influence organizational commitment. He believes that the factors influencing emotional commitment including work characteristics, leadership and membership, roles characteristics,organization structural characteristics and the individual features. Furthermore, factors that affect normative commitment including the specification of requirements, training experience and individual experiences. Moreover, educational background, the application of technology, the possibility of diverted, and the welfare can affect the continuance commitment. Organizational commitment is the independent assessment combined with the work particularity of hotel industry, such as high-intensity work during peak periods, long working hours, responsibilities changes and need to deal with different guests' demands (Buick I. \& Thomas M., 2001). Therefore, work-family conflict will weaken the organizational commitment of female middle managers in hotels. Accordingly, we posit the following hypotheses:

\section{H2: work-family conflict has a significant passive impact on organizational commitment.}

American clinical psychologist Freudenberger (1974) proposed the job burnout concept. He thought that the job burnout performing on two aspects: physical symptoms and behavioral symptoms. After that, Maslach \& Jackson (1981) conducted a series of research around the connotation and measurement of job burnout in service industry. They pointed out job burnout consisting of three factors: the emotional exhaustion, cynicism and lower self-efficacy. Perlman \& Hartman (1982) thought that the job burnout included the following aspects: the feeling of failure and exhaustion, losing creativity, out of work commitment, alienating others, chronic stress reached the limit and often accompanied with uncomfortable physical and emotional symptoms. Later, Maslach (2001) pointed out that job burnout was a response to the continuing negative emotions during ongoing work and interpersonal stress. Work-family conflict will influence women managers' mental state and strengthen their sense of urgency, in particular when they lacking flexibility to fulfill the role of family and work, then these conflicts would enhance the job burnout.At the same time,female managers need to switch the different roles between the hotel and family constantly,it will strengthen the emotional exhaustion (Kossek E. E. \& Cynthia O., 1999). These contradictory roles requirements need female managers to pay a lot of personal resources to cope under different scenarios. thereby increasing their job burnout. Accordingly, we posit the following hypotheses: 


\section{H3: work-family conflict has a significant positive impact on job burnout.}

Women has gradually become the main force in the hotel industry and they are an important part of the hotel human resources.As a special group,hotel female middle managers face more pressure than men in the workplace. In addition, female middle managers are required to be a good staff and to be a qualified wife and mother while facing different evaluation criteria puzzles. Women working in the hotel industry may be suspected by relatives and friends and even family members. Therefore, they have to bear both working pressure and psychological pressure. Combined with the special working conditions of hotel industry,work-family conflict often affects female hotel manager emotions and productivity. What's worse, some of them choose to resign and the conflicts between work and family have a great impact on career development of female middle managers. On the basis of these considerations, we posit the following hypotheses:

\section{H4: work-family conflict has a significant passive impact on work performance.}

Once the employees feel that these conflicts can not be changed, and they can not access the resources to ameliorate the condition, their attitude and behavior will be affected. In the long run, the employees will consider to terminate the relationship to achieve a better balance. Turnover intention refers to the attitudes and ideas generated by employees to leave the organization, which can be used to measure the extent of the employees' leaving. Price \& Mueller (1982) suggested that 13 variables will affect turnover intention including, external opportunities, work routine, job involvement, communication, integration of wages, fair distribution, promotion opportunities, professional training and family responsibilities and so on. High turnover has been a big headache in hotel industry and the academic and hotel practitioners have been paid attention to it.The complex working environment, indeterminate working hours and great role stress will increase work-family conflict, thereby increasing female employees' turnover intention. We propose the last hypotheses:

\section{H5: work-family conflict has a significant positive impact on turnover intention.}

\section{Method}

The object of our study is the female middle managers in the hotel industry and they can affect the organization's management ability substantially. Most of them are department managers (deputy managers) who can virtue of their skills and knowledge to make contribution to the hotels. A prominent feature of them is that most of them are 25-45 years old, this period is an important stage of career development.

We adopted the Work-Family Conflict Scale prepared by Gutek et al. (1991) directly, its' procedures are more rigorous in methodology, and this scale showed both high reliability and validity in many empirical studies later. Family-Work Conflict was measured by Frone et al.'s (1997). On the basis of literature research, we employed validated scales derived from foreign scholars' scales of job satisfaction, organizational commitment, job burnout, job performance and turnover intention. This integrated way of measuring this issue has also been adopted by a large number of researchers to analyze the interactive impact of work-family conflict. All variables in the study were measured on 5-point Likert type scales (1="not at all,"and 5="extremely").

This study used the questionnaire survey to collect data and the information was obtained from 350 female middle managers working in 6 high-star hotels in Guangzhou in January 2016. We distributed a total of 350 finial questionnaires and got 315 valid questionnaires finally, the response rate was $87 \%$. In order to test the reliability and validity of scales, we conducted Cronbach's coefficient alpha test for constructs and principal component analysis by SPSS19.0. Then, we did explained variances test and variance analysis to clarify the differences. Finally, we did hypothesis testing by SPSS19.0.

\section{Results}

\subsection{Profile of respondents}

As presented in Table 1, two dominant age groups were 26-35(69.4\%) and 36-45 (21.0\%) years old. With regard to level of education, $69.1 \%$ of the respondents had higher education (i.e.,university, college), $10.5 \%$ had secondary education, while $20.4 \%$ had post-graduate education (i.e., master). A great number of the respondents were married (81.8\%), while $15.4 \%$ were single, and $2.8 \%$ were divorced. Most of them have one child (71.0\%) and $21.6 \%$ don't have child. With regard the Working time, most female managers work for the hotels for 6-10 years $(50.3 \%), 32.7 \%$ work in hotels for $3-5$ years. They come from different departments: financial department (4.9\%), human resources department (19.8\%), housekeeping department (23.8\%), food and beverage department (15.7\%), front office (13.6\%), purchase department (11.1\%), recreation and entertainment department (11.1\%). 
Table 1. Sample profile

\begin{tabular}{cccccc}
\hline & Frequency & $\%$ & & Frequency & $\%$ \\
\hline Age & & & Marital status & & \\
$20-25$ & 11 & 3.4 & single & 50 & 15.4 \\
$26-35$ & 225 & 69.4 & married & 265 & 81.8 \\
$36-45$ & 68 & 21 & divorced & 9 & 2.8 \\
$46-55$ & 10 & 3.1 & Departments & & \\
55 & 10 & 3.1 & financial & 16 & 4.9 \\
Education level & & & human resources & 64 & 19.8 \\
Secondary education & 34 & 10.5 & housekeeping & 77 & 23.8 \\
University and college & 224 & 69.1 & food \& beverage & 51 & 15.7 \\
Master & 66 & 20.4 & front & 44 & 13.6 \\
Working time & & & purchase & 36 & 11.1 \\
$<3$ years & 51 & 15.7 & recreation\&entertainment & 36 & 11.1 \\
3-5years & 106 & 32.7 & Children & & \\
6-10years & 163 & 50.3 & 0 & 70 & 21.6 \\
$>$ 11years & 4 & 1.2 & 1 & 230 & 71 \\
& & & 2 & 24 & 7.4 \\
\hline
\end{tabular}

\subsection{Reliability and Validity Test}

As shown in Table 2, we collected 315 valid questionnaires in this research, and the reliability of scales was measured by SPSS19.0 through the Cronbach's coefficient alpha for all constructs. In particular, the overall scale's Cronbach coefficient alpha was 0.854 , and all the estimated index were above the threshold of 0.7 for Cronbach's alpha $\left(\alpha\right.$ work-family conflict $=0.867, \alpha_{\text {job satisfaction }}=0 . .801, \alpha$ organizational commitment $=0.807, \alpha$ job burnout $=0.807, \alpha$ work performance $=0.807, \alpha_{\text {turnover intention }}=0.802$ ) which showed good internal consistency of scales.

Table 2. Reliability test

\begin{tabular}{ccc}
\hline & Cronbach's Alpha & items \\
\hline The whole scale & 0.854 & 29 \\
Work-Family Conflict & 0.867 & 9 \\
Job Satisfaction & 0.801 & 4 \\
Organizational Commitment & 0.807 & 6 \\
Job Burnout & 0.843 & 4 \\
Work Performance & 0.822 & 3 \\
Turnover Intention & 0.802 & 3 \\
\hline
\end{tabular}

Then, we performed the principal component analysis to measure the reliability of variables, and the KMO was 0.863 (Table 3), indicating that it's suitable for factor analysis. Also, the explained variances for the scale was $83.194 \%$ (Table 4). 
Table 3. KMO and Bartlett test

\begin{tabular}{lcc}
\hline Kaiser-Meyer-Olkin & 0.863 \\
\hline Bartlett & chi-squared approximation & 18248.842 \\
& df & 406 \\
& Sig. & 0 \\
\hline
\end{tabular}

Table 4. Explained variances test

\begin{tabular}{|c|c|c|c|c|c|c|c|c|}
\hline \multirow{3}{*}{$\begin{array}{c}\text { Composition } \\
1\end{array}$} & \multirow{2}{*}{\multicolumn{3}{|c|}{$\begin{array}{c}\text { Initial Eigenvalues } \\
\text { Total Variance \% Total }\end{array}$}} & \multirow{2}{*}{\multicolumn{2}{|c|}{$\begin{array}{l}\text { Extracting Square and Loa } \\
\text { Variance } \% \text { Accumulation }\end{array}$}} & \multicolumn{3}{|c|}{ Loading and Rotation Square } \\
\hline & & & & & & Total & Jariance & umulation \% \\
\hline & 6.884 & 23.74 & 6.884 & 23.74 & 23.74 & 5.992 & 20.663 & 20.663 \\
\hline 2 & 6.153 & 21.217 & 6.153 & 21.217 & 44.957 & 5.769 & 19.894 & 40.558 \\
\hline 3 & 3.682 & 12.697 & 3.682 & 12.697 & 57.654 & 3.945 & 13.603 & 54.161 \\
\hline 4 & 2.971 & 10.245 & 2.971 & 10.245 & 67.898 & 3.204 & 11.047 & 65.208 \\
\hline 5 & 2.345 & 8.086 & 2.345 & 8.086 & 75.985 & 2.995 & 10.326 & 75.535 \\
\hline 6 & 2.091 & 7.21 & 2.091 & 7.21 & 83.194 & 2.221 & 7.659 & 83.194 \\
\hline 7 & 0.988 & 3.405 & & & & & & \\
\hline 8 & 0.944 & 3.254 & & & & & & \\
\hline 9 & 0.65 & 2.242 & & & & & & \\
\hline 10 & 0.5 & 1.724 & & & & & & \\
\hline 11 & 0.403 & 1.391 & & & & & & \\
\hline 12 & 0.35 & 1.206 & & & & & & \\
\hline 13 & 0.334 & 1.152 & & & & & & \\
\hline 14 & 0.211 & 0.729 & & & & & & \\
\hline 15 & 0.161 & 0.554 & & & & & & \\
\hline 16 & 0.07 & 0.24 & & & & & & \\
\hline 17 & 0.058 & 0.201 & & & & & & \\
\hline 18 & 0.041 & 0.141 & & & & & & \\
\hline 19 & 0.031 & 0.108 & & & & & & \\
\hline 20 & 0.029 & 0.1 & & & & & & \\
\hline 21 & 0.024 & 0.084 & & & & & & \\
\hline 22 & 0.023 & 0.079 & & & & & & \\
\hline 23 & 0.018 & 0.061 & & & & & & \\
\hline 24 & 0.012 & 0.042 & & & & & & \\
\hline 25 & 0.011 & 0.037 & & & & & & \\
\hline 26 & 0.007 & 0.026 & & & & & & \\
\hline 27 & 0.003 & 0.012 & & & & & & \\
\hline 28 & 0.003 & 0.011 & & & & & & \\
\hline 29 & 0.003 & 0.009 & & & & & & \\
\hline
\end{tabular}




\subsection{Variance Analysis}

In order to clarify the different stages of work and family lives as well as different departments whether have different influences on female middle managers' professional career development in hotels, we conducted variance analysis by SPSS19.0 (Table 5). The result showed that female middle managers perceive varying degrees of conflict significantly during different marital status and family stages, because there are different requirements and changes under different circumstances of family and work lives. When they got married and gave birth to a baby, because of the stress and responsibilities of a wife and mother, they must pay more attention to families,and reallocate resources again to work. At this time,the perceived pressure will strengthen work-family conflict, and the disturbance from family can also distract employees during working time. Furthermore, there are cognitive differences between different departments.Female managers working at front office and food \& beverage departments often interact with customers and they have to obey more constraints, while they enjoying greater freedom at home and rejecting such constraints and giving. Finally, female managers who work longer for hotels perceive less conflicts since they are accustomed to the working environment and are familiar with business. On the other hand,their children are older, so they can concentrate on work.

Table 5. Variance analysis results

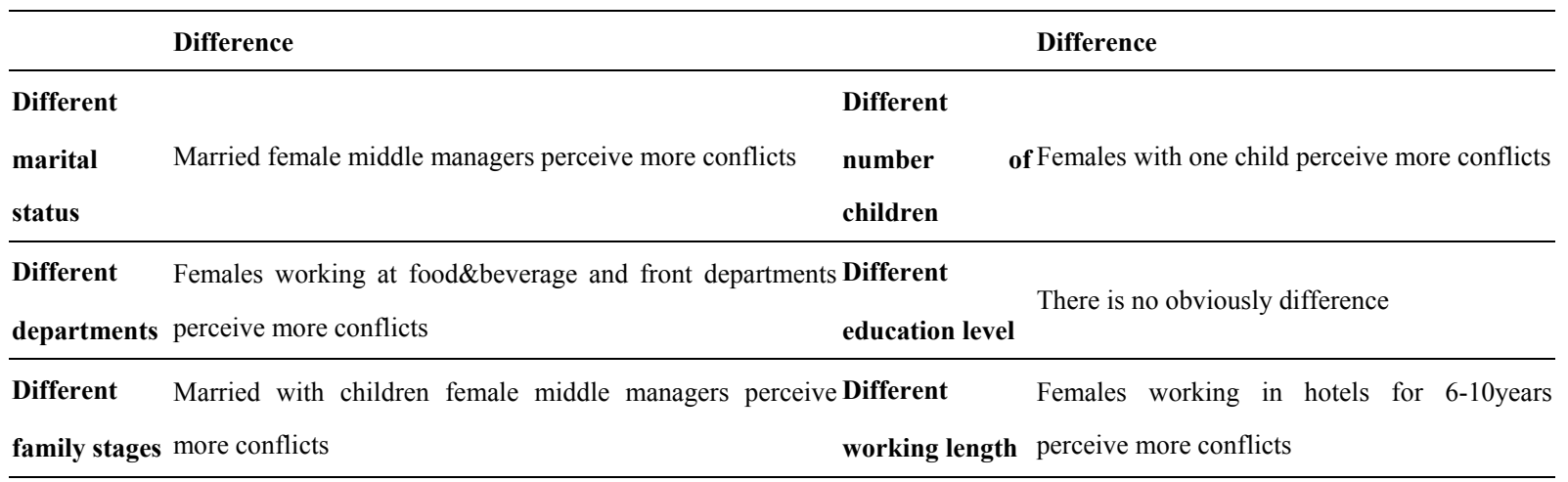

\subsection{Hypotheses Testing}

Pearson correlation analysis was performed to test the correlation between work-family conflict, job satisfaction, organizational commitment, job burnout, work performance and turnover intention. There was a significant passive correlation between job satisfaction and work-family conflict, the correlation coefficient was -0.286 providing evidence in favor of $\mathrm{H} 1$. Meanwhile, organizational commitment was passively correlated with work-family conflict, thus, $\mathrm{H} 2$ was supported. The results showed that the relationship between job burnout and work-family conflict was strong and the correlation coefficient was 0.081 . Moreover, work performance was passively correlated with work-family conflict. Furthermore,the results confirmed that female managers' turnover intention was interrelated positively with work-family conflict and the correlation coefficient was 0.112 . Therefore, H3, H4 and H5 were supported (Table 6).

Table 6. Hypotheses testing results

\begin{tabular}{lllllll}
\hline & & $\begin{array}{l}\text { Job } \\
\text { Satisfaction }\end{array}$ & $\begin{array}{l}\text { Organizational } \\
\text { Commitment }\end{array}$ & $\begin{array}{l}\text { Job } \\
\text { Burnout }\end{array}$ & $\begin{array}{l}\text { Work } \\
\text { Performance }\end{array}$ & $\begin{array}{l}\text { Turnover } \\
\text { Intention }\end{array}$ \\
\hline $\begin{array}{l}\text { Work-Family } \\
\text { Conflict }\end{array}$ & Pearson & $-0.286^{* *}$ & $-0.278^{* *}$ & $0.081^{*}$ & $-0.162^{* *}$ & $0.112^{*}$ \\
& Sig & 0 & 0 & 0.014 & 0.003 & 0.044 \\
& & & & & \\
\hline$* * * . p<.001 ; * * . p<0.01 ; * \mathrm{p}<0.05$. & & & & & & \\
\hline
\end{tabular}




\section{Conclusion, Discussion and Limitations}

\subsection{Conclusions and Discussion}

The results demonstrated that female middle managers working in the hotel industry face significant work-family conflict. Traditional social values make more demands on females that they have to take on more responsibilities in family. The stress of family character makes it hard to complete another role's requirement. Job satisfaction of female employees is influenced by the combined impact of work and family. When the conflicts are intense, their psychological capital and job satisfaction will be affected adversely. We also found that when work-family conflict influences the female managers significantly, while the hotel fails to take positive and effective mitigation measures to relieve the stress, their organizational commitment will be weaken. Moreover, work-family conflict will lead to emotional exhaustion and emotional alienation tendencies of female employees, and will result in lower professional efficacy, thereby strengthening job burnout.

Emotional spending is the basic connotation of the hotel employees, but long term conflicts will cause fatigued state of physical and mental. As the antithesis of emotion spending, work-family conflict brings lower job satisfaction, organizational commitment and higher job burnout. What's worse, it will reduce work performance of female managers, in the long run it will weaken the service quality of hotels. Finally, high turnover intention is considered as one of the top issues in the hospitality industry.Work-family conflict will strengthen females' turnover intention, which not only has a negative effect on their career development, but also is harmful to development of female human resources in the hotel industry.

It's true that satisfied and loyal staff are those who build customers satisfaction which demonstrates the importance of caring for working staff. Those who are dissatisfied with the hotels are much less likely to provide favorable service. According to the conclusions of research, we would like to give the following managerial suggestions and opinions.

Firstly, implementing flexible management to weaken the pressure conflict and time conflict of female managers. The hotels should pay attention to females' demands and take the mission of helping employees achieve a balance. And the hotels can also provide opportunities for employees' family members to visit the hotels and know the job content so that they can understand and support female managers. Moreover, the hotels are supposed to provide consultation service and psychological guidance for their stuff on family problems and pressure comforting when necessary. Further, the hotels can share some welfare to female managers' families and help them overcome difficulties to relieve mental pressure, instead of only focusing on "managing" but ignoring "emotion".

Designing family supporting programs for female managers, and try to help them solve troubles as far as possible. This programs' starting point is using the resources of enterprises to corporate employees deal with the stress according to different needs of females, including job sharing plan, communication plan, families seminars, childcare and pension services to improve their job satisfaction, job performance and organization citizens behaviors.

Based on the data of survey, it is normal that staff get the symptoms of jadedness, it will not only eventually lead to resignation, but also have the negative effect on the quality of service. Therefore the change of staff's emotion should be paid enough attention, and find an outlet to relieve the emotional exhaustion by organizing a variety of extracurricular activities, training and competition, so that to avoid the negative impact on both of the employees and enterprises.

Organization intervention and family support are external factors of alleviating work-family conflict. However, female managers own coping capacity is the rudimentary way. Therefore, female managers need to find out the emphasis between family and work. Setting priorities is one of the keys to ease the conflicts. At the same time, they should promote personal ability, improve the self-efficacy, deal with the pressure by reasonable way and make a better combination between career decision and family responsibilities, gradually, alleviating the negative influence of work-family conflict and achieving the balance of work and family.

\subsection{Limitations and Recommendations for Future Research}

This paper makes several contributions. First,we concerned about and attracted more attention to this special group of female middle managers in the hotel industry. Second, the impact of work-family conflict on female middle managers is studied in the hospitality industry. Third, we examined the relationship among these variables (i.e.,work-family conflict, job satisfaction, organizational commitment, job burnout, work performance and turnover intention).

However, some limitations of this study could be considered as opportunities for the future research. First, the 
paper concern only six hotels segment in Guangzhou, which imposes caution for their generalization. Therefore, we suggest future research to approach more hotels in other cities. In addition,we employed validated scales derived from the translation of foreign scholars. But in the Chinese cultural background, it is better to revise these conceptual structures. We distributed and collected the questionnaires through managers, so that we can not control the processes or answer the questions very well. Moreover, some other variables could be included in the model, such as, communication, service climate and organizational justice. So, future studies could add in these variables to improve the model.

\section{References}

Allen, N. J., \& Meyer, J. P. (1990).The Measurement and Antecedents of Effective, Continuance and Normative Commitment to The Organization. Journal of Occupational Psychology, 63(1), 1-18. http://dx.doi.org/10.1111/j.2044-8325.1990.tb00506.x

Brass, J. D. (1985). Men's and women's networks: A Study of Interaction Patterns and Influence in An Organization. Academy of Management Journal, 28(2), 327-343. http://dx.doi.org/10.2307/256204

Brownell, J. (1991). SHA Tracking Study. NY: School of Hotel Administration, Cornell University. Unpublished paper, pp31.

Brownell, J. (1994). Women in Hospitality Management: General Managers' Perceptions of Factors Related to Career Development. International Journal of Hospitality Management, 13(2), 101-117. http://dx.doi.org/10.1016/0278-4319(94)90032-9

Buick, I., \& Thomas, M. (2001). Why Do Middle Managers in Hotels Burnout. International Journal of Contemporary Hospitality Management, 13(6), 304-309. http://dx.doi.org/10.1108/EUM0000000005968

Chen, X. Q. (2003). The Impact of Female Sex Advantages on Hotel Management Mode. Modern Forum, (5), 34-36.

Chusmir, L. H. (1986). Gender Differences in Variables Affecting Job Commitment Among Working Men and Women. Journal of Social Psychology, 87-94. http://dx.doi.org/10.1080/00224545.1986.9713574

Edgar, H. S. (1992). Gender Differences in Managerial Careers: Yesterday, Today, and Tomorrow. Journal of Business Ethics, 37(1), 5-24.

Freudenberger, H. J. (1974). Staff Burnout. Journal of Social Issues, 30(1), 159-165. http://dx.doi.org/10.1111/j.1540-4560.1974.tb00706.x

Frone, M. R., Yardley, J. K., \& Markel, K. S. (1997). Developing and Testing an Integrative Model of The

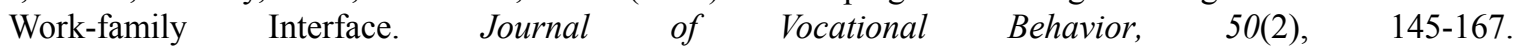
http://dx.doi.org/10.1006/jvbe.1996.1577

Greenhaus, J. H., \& Beutell, N. J. (1985). Sources of Conflict Between Work and Family Roles. Academy of Management Review, 10(1), 76-88.

Gutek, B. A., Searle, S., \& Klcpa, L. (1991). Rational Versus Gender Role Explanations for Work family Conflict. Journal of Applied Psychology, 76(4), 560-568. http://dx.doi.org/10.1037/0021-9010.76.4.560

Kopelman, R. E., Greenhaus, J. H., \& Connolly, T. F. (1983). A Model of Work, Family, and Interrole Conflict: A Construct Validation Study. Organizational Behavior and Human Performance, 32, 198-215. http://dx.doi.org/10.1016/0030-5073(83)90147-2

Kossek, E. E., \& Cynthia, O. (1999). Bridging The Work-family Policy and Productivity Gap: A Literature Review. Community Work \& Family, 2(1), 7-32. http://dx.doi.org/10.1080/13668809908414247

Liu, X. P., \& Wang, C. M. (2001). The Study of Organizational Commitment and Its Development Mechanism. Nankai Business Review, 4(6), 58-62.

Luo, J. L. (2012). Female Career Research Consensus and Future Prospects Contradiction. Foreign Economics \& Management, 34(8), 57-63.

Maslach, C., \& Jackson, S. E. (1981). The Measurement of Experienced Burnout. Journal of Occupational Behavior, 2(2), 99-113. http://dx.doi.org/10.1002/job.4030020205

Maslach, C., Schaufeli, W. B., \& Leiter, M. P. (2001). Job burnout. Annual Review of Psychology, 52(1), 397-422. http://dx.doi.org/10.1146/annurev.psych.52.1.397

Marks, N. F. (1998). Does it Hurt to Care? Care giving, Work-family Conflict, and Midlife Well-being. Journal of Marriage and the Family, (4), 951-966. http://dx.doi.org/10.2307/353637 
Perlman, B., \& Hartman, E. A. (1982). Burnout: Summary and Future Research. Human Relations, 35(4), 283-305. http://dx.doi.org/10.1177/001872678203500402

Pleck, J., \& Stines, G. (1984). Work Schedules and Family Life in Two-earner Couple. Journal of Applied Psychology, (69), 515-523.

Price, J. L., \& Mueller, C. W. (1982). A Causal Model of Turnover For Nurses. Academy of Management Journal, 24(3), 543-565. http://dx.doi.org/10.2307/255574

Shi, K. (2015). Organization Ethical Climate's Affect on Employee Conflicts: Regulation of Transformational Leadership. Modern Management Science, (7), 3-6.

Yang, H. L. (2012). Causes of Chinese Modern Females' Role Conflict Analysis and Countermeasures. Theoretical Research, (3), 263-264.

Zhang, Z. S. (2002). Work-family Relations Theory and Work-family Balance Program. Nankai Business Review, (4), 55-59.

\section{Copyrights}

Copyright for this article is retained by the author(s), with first publication rights granted to the journal.

This is an open-access article distributed under the terms and conditions of the Creative Commons Attribution license (http://creativecommons.org/licenses/by/4.0/). 